\title{
GOLPH3: a novel biomarker that correlates with poor survival and resistance to chemotherapy in breast cancer
}

\author{
Shicong Tang ${ }^{1}$, Hong Pan ${ }^{2}$, Wei Wei ${ }^{1}$, Huawei Yang ${ }^{1}$, Jianlun Liu ${ }^{1}$ and Rirong Yang ${ }^{3}$ \\ ${ }^{1}$ Department of Breast Surgery, Affiliated Tumor Hospital of Guangxi Medical University, Nanning, Guangxi, People's Republic \\ of China \\ ${ }^{2}$ Department of Thoracic Surgery, Affiliated Tumor Hospital of Guangxi Medical University, Nanning, Guangxi, People's \\ Republic of China \\ ${ }^{3}$ Department of Immunology, School of Preclinical Medicine, Guangxi Medical University, Guangxi, People's Republic of China \\ Correspondence to: Rirong Yang, email: 520yrr@163.com \\ Jianlun Liu, email: liu_jianlun@126.com
}

Keywords: GOLPH3; breast cancer; chemotherapy; survival

Received: May 19, $2017 \quad$ Accepted: August 04, 2017

Published: October 19, 2017

Copyright: Tang et al. This is an open-access article distributed under the terms of the Creative Commons Attribution License 3.0 (CC BY 3.0), which permits unrestricted use, distribution, and reproduction in any medium, provided the original author and source are credited.

\section{ABSTRACT}

The association between Golgi phosphoprotein 3 (GOLPH3) and clinical pathological characteristics, as well as the clinical outcomes of both neoadjuvant and adjuvant chemotherapies in breast cancer, remain largely unknown. In this study, we investigated the biological role and clinical significance of GOLPH3 in breast cancer. We found that GOLPH3 expression in tumor tissue was higher than that in adjacent noncancerous tissue (ANT) and fibroadenoma. GOLPH3 silencing reduced the migration, invasion, and proliferation of breast cancer cells and promoted apoptosis of the cells. Importantly, patients with high GOLPH3 expression had worse disease-free survival (DFS) and overall survival (OS), and GOLPH3 expression was correlated with clinical pathological characteristics such as molecular subtype, tumor-node-metastasis classification, and age but was not associated with surgery type. Patients with high GOLPH3 expression had poor DFS and OS in every molecular subtype, and an increase in tumor invasion and lymph node metastasis. The risk of recurrence increased with age in patients with high GOLPH3 expression, and surgery type had no influence on patient survival. This is the first study to investigate the correlation between GOLPH3 and response to chemotherapy in breast cancer. Patients with high GOLPH3 expression showed resistance to neoadjuvant and adjuvant chemotherapies, and GOLPH3 overexpression indicated a high risk of recurrence in patients who received adjuvant chemotherapy. These data suggest that GOLPH3 may be a novel biomarker that correlates with poor survival and resistance to chemotherapy in breast cancer.

\section{INTRODUCTION}

Breast cancer is the most common malignant tumor in females worldwide [1-3], and its incidence is increasing [4]. Tumor invasion and metastasis are the major causes of treatment failure in this disease; thus, it is important to discover novel molecular biomarkers that can serve as targets for its diagnosis and treatment.

Golgi phosphoprotein 3 (GOLPH3, also named GMx33 or GPP34) and its interacting proteins are hot topics in cancer research [5-7]. GOLPH3 is a highly conserved 34-kDa trans-Golgi matrix membrane protein that plays a key role in receptor recycling, glycosylation, and protein trafficking from Golgi to the plasma membrane [8-11]. Its expression is associated with tumor migration and proliferation in some cancers such as bladder, lung, ovarian epithelial, prostate, liver, rectal, and kidney cancers [18, 20-25]. It is suggested that GOLPH3 functions as an oncogene in tumorigenesis and migration [12-15] by activating the mechanistic target of rapamycin 
(mTOR), Wnt, and nuclear factor kappa-light-chainenhancer of activated B cells (NF-kB) signaling pathways and by upregulating matrix metalloproteinases (MMPs) such as MMP-2 and MMP-9 [16-19]. Zeng et al. [26] found that GOLPH3 is highly expressed in breast cancer, but its function needs further investigation.

Some reports have shown that higher levels of GOLPH3 are associated with a worse prognosis as determined by disease-free survival (DFS) or overall survival (OS). For example, high GOLPH3 overexpression correlates with a worse DFS in small cell lung cancer [18] [23], prostate cancer [21], ovarian epithelial cancer [20], hepatoma carcinoma [22], and rectal carcinoma [25]. It is also correlated with poor OS in renal cell carcinoma [24] and breast cancer [26]. However, little is known about the role that GOLPH3 plays in patients' response to breast cancer treatment. Thus, additional studies are needed to explore the relationship between GOLPH3 expression and clinical outcomes and response to therapy.

In this study, we analyzed the expression of GOLPH3 in breast cancer and its effects on migration and proliferation in breast cancer cell lines. Then we investigated the association between GOLPH3 expression and clinical characteristics to determine if GOLPH3 expression affects recurrence, OS, and the response to neoadjuvant chemotherapy.

\section{RESULTS}

\section{GOLPH3 is highly expressed in breast cancer tissue and cell lines}

To assess GOLPH3 expression in tumor tissues, adjacent noncancerous tissue (ANT), and fibroadenomas, quantitative PCR (qPCR), immunohistochemistry, and Western blotting were performed. Compared with ANT and fibroadenomas, there were significantly higher levels of GOLPH3 in breast cancer tissues and no significant difference in expression between ANT and fibroadenomas (Figure 1A). In addition to tissue samples, the expression of GOLPH3 in two types of breast cancer cell lines was examined: the MDA-MB-231 cell line, which has a high potential of invasiveness, had higher GOLPH3 expression than the MCF-7 cell line (Supplementary Figure 1A). The immunohistochemistry results showed that GOLPH3 expression levels could be classified into,+++ , and +++ (Figure 1B). Moreover, its expression increased as the tumor-node-metastasis (TNM) classification increased (Figures 1C, 1D).

\section{Silencing of GOLPH3 expression reduces cell migration, invasion, proliferation and promotes the apoptosis of breast cancer cells}

To elucidate whether GOLPH3 affects cell migration, invasion, and proliferation, short interfering RNA (siRNA) was successfully transfected into the MCF-7 and MDAMB-231 breast cancer cell lines. The downregulation of GOLPH3 was confirmed by qPCR and Western blotting (Supplementary Figure 1B). The migration and invasion of breast cancer cells were significantly reduced in cells transfected with GOLPH3-siRNA compared with parent cell lines and cells transfected with scram-siRNA $(p<0.05)$ (Figure 2A). No significant difference was found between parent cell lines and cells transfected with scram-siRNA (Figure 2A). Cell proliferation assessed by the CCK8 cell viability assay showed that cells transfected with GOLPH3-siRNA had reduced proliferation compared with parent cell lines and cells transfected with scram-siRNA (Figure 2B). These data indicate that silencing of GOLPH3 suppresses breast cancer cell migration, invasion, and proliferation. To investigate how GOLPH3 expression influences cell apoptosis, the Annexin V FITC apoptosis detection kit was used followed by flow cytometry. In both MDA-MB-231 and MCF-7 cell lines, there was a greater accumulation of early apoptotic cells in GOLPH3-siRNA cells compared with parental and scram-siRNA cells, indicating that GOLPH3 knockdown induced breast cancer cell apoptosis (Figure 2C).

\section{GOLPH3 overexpression was associated with worse survival in breast cancer patients}

The clinical pathological characteristics of the 249 breast cancer patients are summarized in Table 1 and Supplementary Table 1, and no patients were lost during follow-up. We analyzed the correlation between GOLPH3 expression and age, $\mathrm{T}$ classification (tumor invasion depth), $\mathrm{N}$ classification (lymphatic metastasis), $\mathrm{M}$ classification (distant metastasis), molecular subtype, and surgery type. GOLPH3 expression was associated with T classification $(\mathrm{p}=0.033), \mathrm{N}$ classification $(\mathrm{p}<0.001)$, $M$ classification $(p<0.001)$, molecular subtype $(p=0.012)$, and surgery type $(\mathrm{p}<0.001)$. Compared with patients with low GOLPH3 expression, patients with high expression had worse DFS and OS (Figure 3A). Univariate analysis showed that $\mathrm{T}, \mathrm{N}$, and $\mathrm{M}$ classifications, molecular subtype, and GOLPH3 expression were associated with DFS and OS (Table 2), and multivariate analysis showed that these factors were important prognostic factors for the DFS of breast cancer patients (Table 3). Moreover, $\mathrm{N}$ classification, molecular subtype, and GOLPH3 overexpression were highly correlated with the OS of breast cancer patients (Table 3). Taken together, these data indicate that GOLPH3 is an independent prognostic factor for DFS and OS in breast cancer. Interestingly, we found that patients with GOLPH3 overexpression had poor DFS and OS in every molecular subtype. For example, in patients with luminal A breast cancer, high GOLPH3 expression correlated with poor DFS $(p=0.0208)$ and OS $(p=0.0408)$ (Figure 3B). Similar results were observed for both DFS and OS in other molecular subtypes (luminal 
B1, luminal B2, human epidermal growth factor receptor 2-positive, and triple-negative breast [TNB]; Figures 3C$3 \mathrm{~F})$. However, the difference in both DFS and OS across the five molecular subtypes was not significant (DFS: $\mathrm{p}=0.6979$, OS: $\mathrm{p}=0.6527$ ) (Supplementary Figures 2A, 2B). Similarly, in patients with low GOLPH3 expression, no significant differences in DFS and OS among the five molecular subtypes were found (DFS: $p=0.7547$, OS: $\mathrm{p}=0.4734)$ (Supplementary Figures 2A, 2B).

\section{Association of age, TNM classification, and survival with GOLPH3 expression}

Although the results shown in Table 1 indicated that there was no statistically significant difference in mean patient age between those with high and low GOLPH3 expression $(\mathrm{p}=0.080)$, we categorized age into four groups $(<40,40-50,50-60,>60)$ to evaluate the effect of GOLPH3 expression on each group. In patients $<40$ years
A
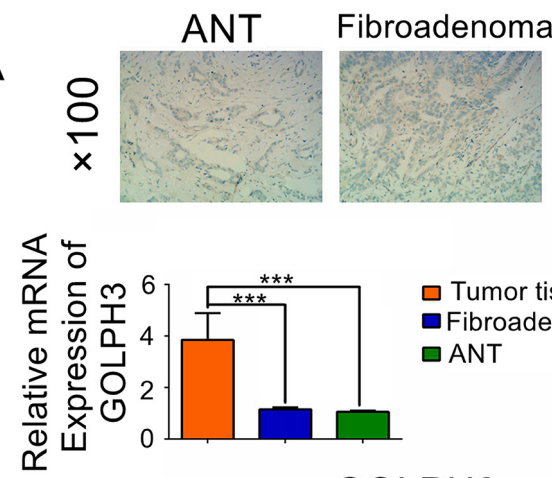

B

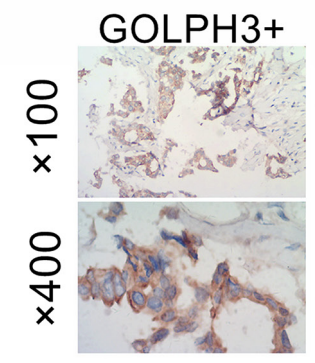

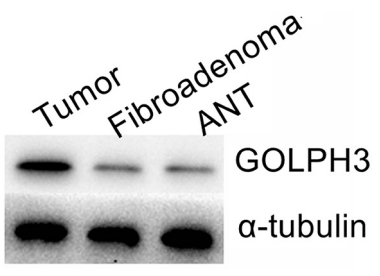

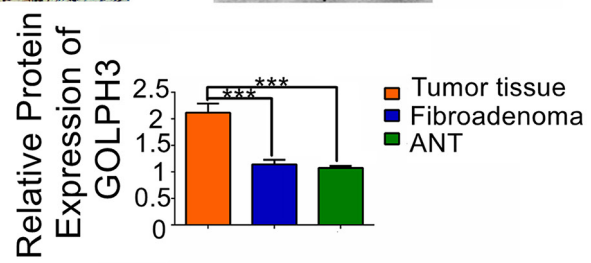

C
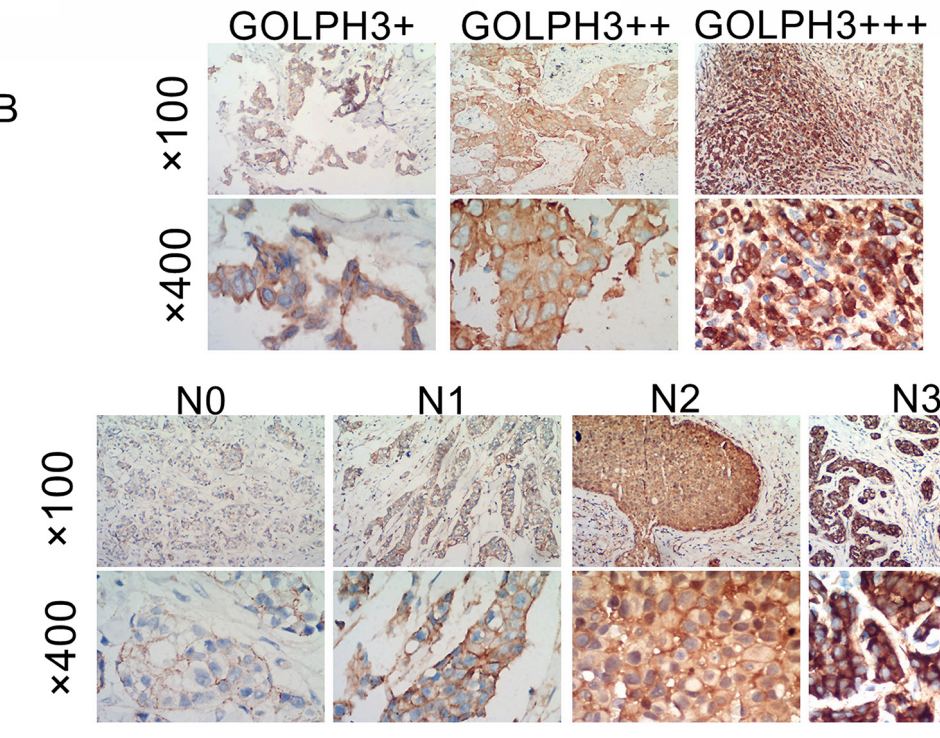

N2

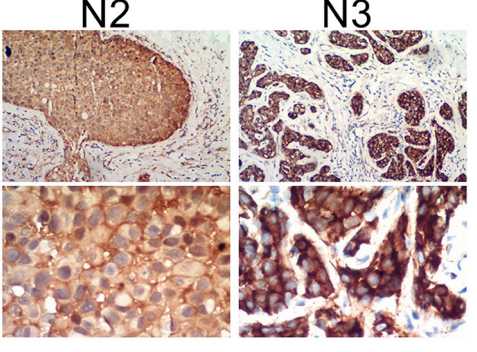

D
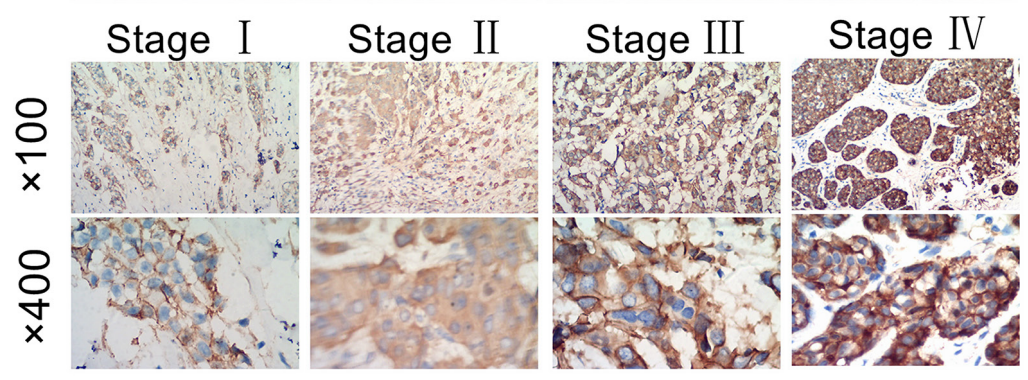

Figure 1: GOLPH3 is overexpressed in breast cancer. (A) GOLPH3 expression in breast cancer tissue is higher than that in adjacent noncancerous tissues (ANTs) and fibroadenoma, as determined by immunohistochemistry, Western blotting, and real-time PCR. (B) GOLPH3 expression was demonstrated by immunohistochemistry. (C) GOLPH3 protein expression in patients with different grades of lymph node metastasis was detected by immunohistochemistry. (D) GOLPH3 protein expression in patients at different clinical stages was detected by immunohistochemistry. All values are shown as the mean \pm SD of three independent experiments. ${ }^{* * *}, p<0.001$. 
of age, those with GOLPH3 overexpression did not have an increased risk of breast cancer recurrence $(p=0.5659)$, but their OS was significantly poorer $(p=0.0187)$ (Supplementary Figure 2C). Interestingly, patients with high GOLPH3 expression in the other three age groups had poorer DFS and OS compared with those with low GOLPH3 expression (Supplementary Figures 2D-2F).
There was no statistical significance in DFS and OS in patients with low GOLPH3 expression among the four age groups (Supplementary Figure 2G). Importantly, the risk of recurrence increased with age in patients with GOLPH3 overexpression (Supplementary Figure 2H); however, no significant difference in OS was observed in the four age groups (Supplementary Figure 2H). GOLPH3 expression
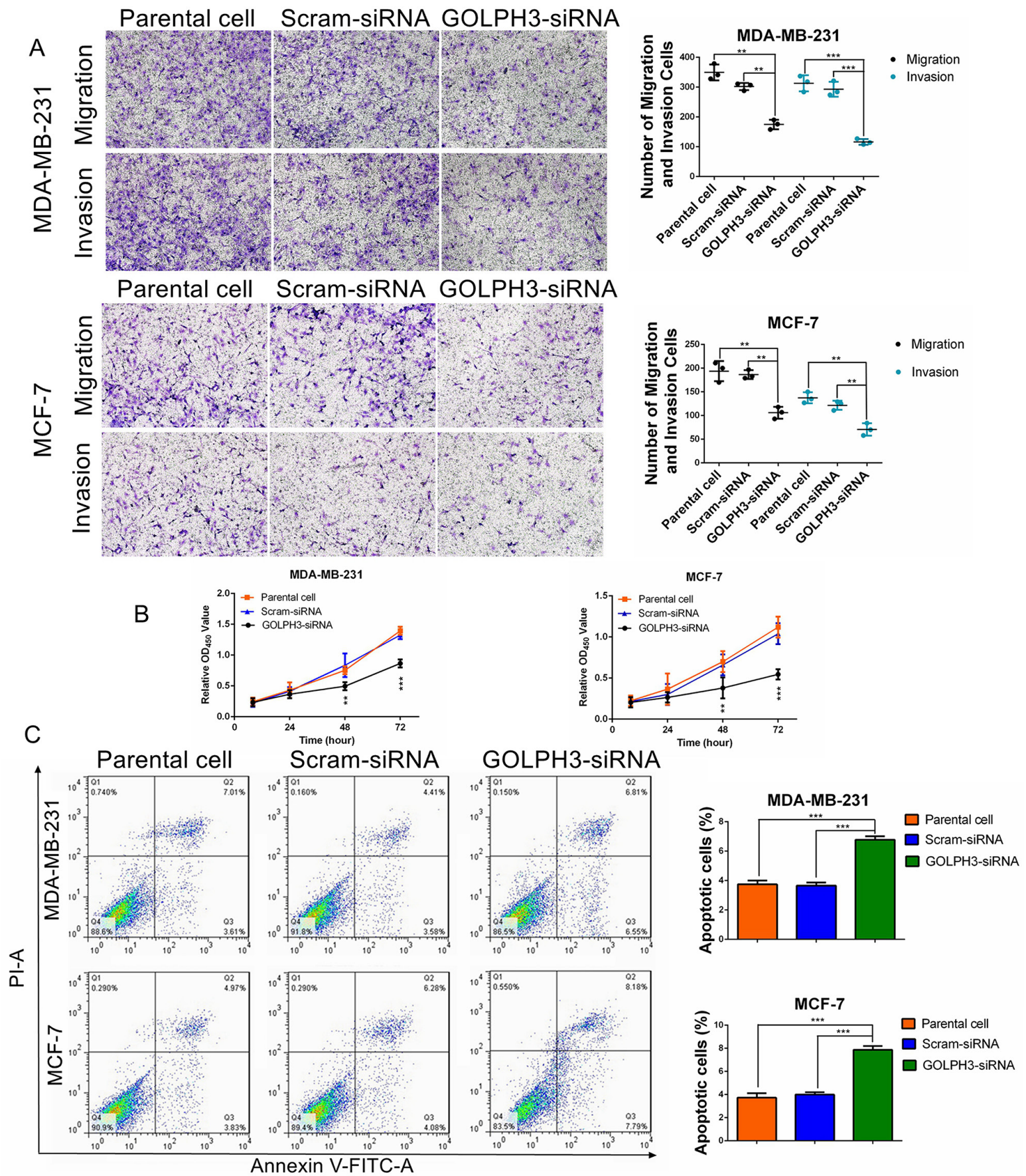

Figure 2: GOLPH3 silencing inhibits breast cancer cell migration, invasion, and proliferation, and promotes apoptosis. (A) Downregulation of GOLPH3 reduced breast cancer cell migration and invasion. Magnification 100×. (B) GOLPH3 silencing suppressed the proliferation of both MDA-MB-231 and MCF-7 cells. (C) GOLPH3 silencing promoted the apoptosis of both MDA-MB-231 and MCF7 cells. All values are the mean $\pm \mathrm{SD}$ of three independent experiments. ${ }^{* *}, p<0.01{ }^{* * *}, p<0.001$. 
was highly correlated with tumor invasion depth $(p=0.033)$ (Table 1). We also assessed DFS and OS in patients with GOLPH3 expression as well as tumor invasion depth in patients with T1-T4 lesions. For patients with T1 or T2 lesions, high GOLPH3 expression led to poorer DFS and OS compared with those with low GOLPH3 expression (T1, DFS: $p=0.0103$; OS, $p=0.0101 ;$ T2, DFS: $p<0.0001$; OS: $p<0.0001$ ) (Supplementary Figures 3A, 3B). However, in patients with $\mathrm{T} 3$ or T4 lesions, there was no significant difference in DFS or OS between patients with high or low GOLPH3 expression (T3, DFS: $p=0.1389$, OS: $p=0.1270$; T4, DFS: $p=0.1203$, OS: $p=0.4716$ ) (Supplementary Figures $3 \mathrm{C}, 3 \mathrm{D})$. For patients with high GOLPH3 expression, T3 and T4 lesions indicated poor DFS $(\mathrm{p}=0.0360)$ but not poor OS $(p=0.7521)$ (Supplementary Figure $3 F)$. For patients with low GOLPH3 expression, an increase in tumor invasion depth correlated with worse DFS $(p=0.0186)$ and $\operatorname{OS}(p=0.0222)$ (Supplementary Figure 3E). The relationship between GOLPH3 expression and lymphatic metastasis was also observed in our study $(\mathrm{p}<0.001)$ (Table 1). For patients without lymphatic metastasis (N0), high GOLPH3 expression indicated poor DFS $(\mathrm{p}=0.0004)$ and OS $(p=0.0166)$ (Supplementary Figure 4A). However, for patients with lymphatic metastasis (N1 and N2), GOLPH3 expression appeared to have no influence on DFS and OS (N1, DFS: $p=0.3957$, OS: $p=0.6825$; N2, DFS: $p=0.4373$, OS: $p=0.6775$ ) (Supplementary Figures 4B, 4C). In patients with low GOLPH3 expression, the increase in lymphatic metastasis correlated with poorer DFS $(p<0.0001)$ rather than OS ( $p=0.3053)$ (Supplementary Figure 4D). While in patients with high GOLPH3 expression, the increase in lymphatic metastasis led to a worse DFS $(\mathrm{p}=0.0012)$ and OS $(p<0.0001)$ (Supplementary Figure 4E).

\section{Surgery type has no influence on the survival of patients with high GOLPH3 expression}

Besides disease characteristics, we focused on the relationship between GOLPH3 expression and surgery type (breast conserving surgery, simple mastectomy, modified radical mastectomy, section resection) to find a suitable surgery type for patients with GOLPH3 overexpression. In the cohort of patients who received breast-conserving surgery, 17 had high GOLPH3 expression and 1 had low expression. Because of the small number of patients, no effects of GOLPH3 expression were found on DFS and $\mathrm{OS}$ in patients receiving breast-conserving surgery (Supplementary Figure 5A). The same results were observed in patients who received simple mastectomy and section resection (Supplementary Figures 5B, 5C). High GOLPH3 expression was associated with poorer DFS and OS in patients who received modified radical mastectomy, $(p<0.0001)$ (Supplementary Figure 5D), whereas low expression had no effect on DFS and OS regardless of surgery type (Supplementary Figure 5E). In patients with high GOPH3 expression, the results of DFS and OS showed that there was a significant difference across the four surgery types (DFS: $p=0.0240$, OS: $p=0.0182$ ) (Supplementary Figure 5F). However, these results were based on data from a small number of patients; thus, future studies are needed with a larger cohort of patients to confirm these results.

\section{High GOLPH3 expression is correlated with neoadjuvant chemotherapy resistance in breast cancer patients}

In our study, 54 patients received neoadjuvant chemotherapy. The partial response (PR) in 36 patients with high GOLPH3 expression was lower than that in the 18 patients with low expression $(\mathrm{p}=0.021)$ (Table 4$)$. In this patient cohort, 22 patients received the anthracycline +taxane+cyclophosphamide regimen, 20 received the 5-fl uorouracil+anthracycline+cyclophosphamide regimen, and 12 received other regimens. In the group treated with the anthracycline+taxane+cyclophosphamide regimen, the PR in the 14 patients with high GOLPH3 expression had lower PR rates $(6 / 14)$ than the 8 patients with low GOLPH3 expression ( $p=0.05$ ) (Table 5). In the group of patients who underwent 5-fluorouracil+anthracycline $+\mathrm{c}$ yclophosphamide and other regimens, the PR rates were not statistically different between high and low GOLPH3 expression ( $\mathrm{p}=0.492$ and $\mathrm{p}=0.296$, respectively) (Table 5).

\section{High GOLPH3 expression is correlated with high recurrence rate in breast cancer patients who received adjuvant chemotherapy}

We also evaluated the relationship between GOLPH3 expression and breast cancer recurrence in patients who received adjuvant chemotherapy after surgery. A total of 216 patients received adjuvant chemotherapy after surgery. Patients with high GOLPH3 expression $(n=103)$ showed poorer DFS and OS compared with those with low expression ( $\mathrm{n}=113$ ) (DFS: $\mathrm{p}<0.0001$, OS: $\mathrm{p}<0.0001$ ) (Figure 3G). Among the patients who received adjuvant chemotherapy, 74 received the anthracycline+cyclophosphamide sequential taxane regimen. Patients with high GOLPH3 expression had a higher risk of recurrence $(\mathrm{p}=0.035)$ (Table 6) and poor OS $(\mathrm{p}=0.0015)$ (Figure $3 \mathrm{H}$ ). Among those who received adjuvant chemotherapy, 79 patients received 5-fluorouracil+anthra cycline+cyclophosphamide. Patients with high GOLPH3 expression had the same risk of recurrence and death as those who received anthracycline+cyclophosphamide sequential taxane regimen (DFS: $\mathrm{p}=0.010, \mathrm{OS}: \mathrm{p}=0.0017$ ) (Table 6 and Figure 3I). Of the 30 people who received taxane+cyclophosphamide regimen, no significant difference in recurrence or OS was observed between those with high and low GOLPH3 expression (DFS: $\mathrm{p}=0.190$, OS: $\mathrm{p}=0.2129$ ) (Table 6, Figure 3J). In patients who received other chemotherapy regimens, GOLPH3 overexpression 


\section{Survival of All Patients and Patients with Different Molecular Subtype}
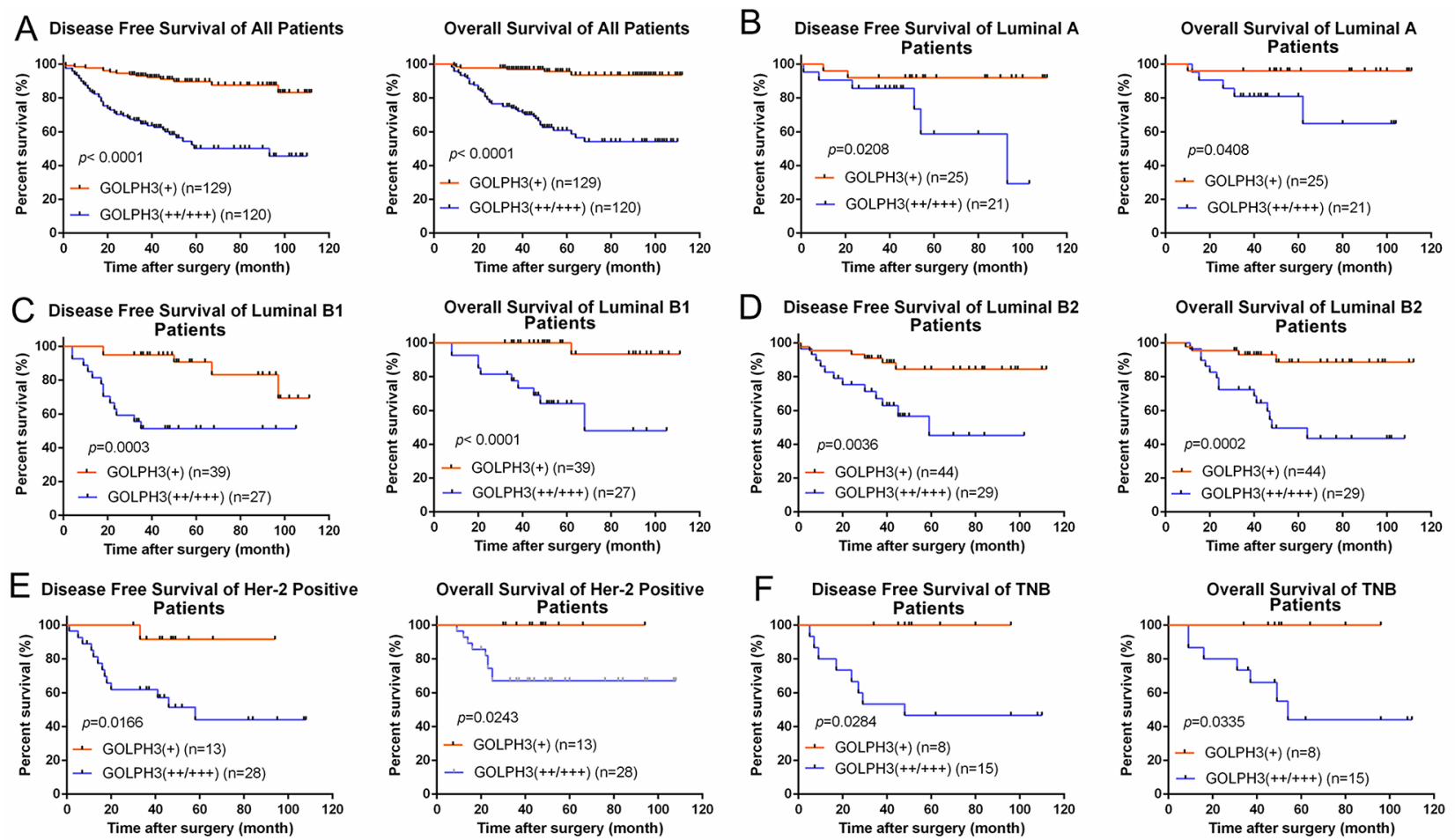

\section{Overall Survival of Patietns Received Adjuvant Chemotherapy}
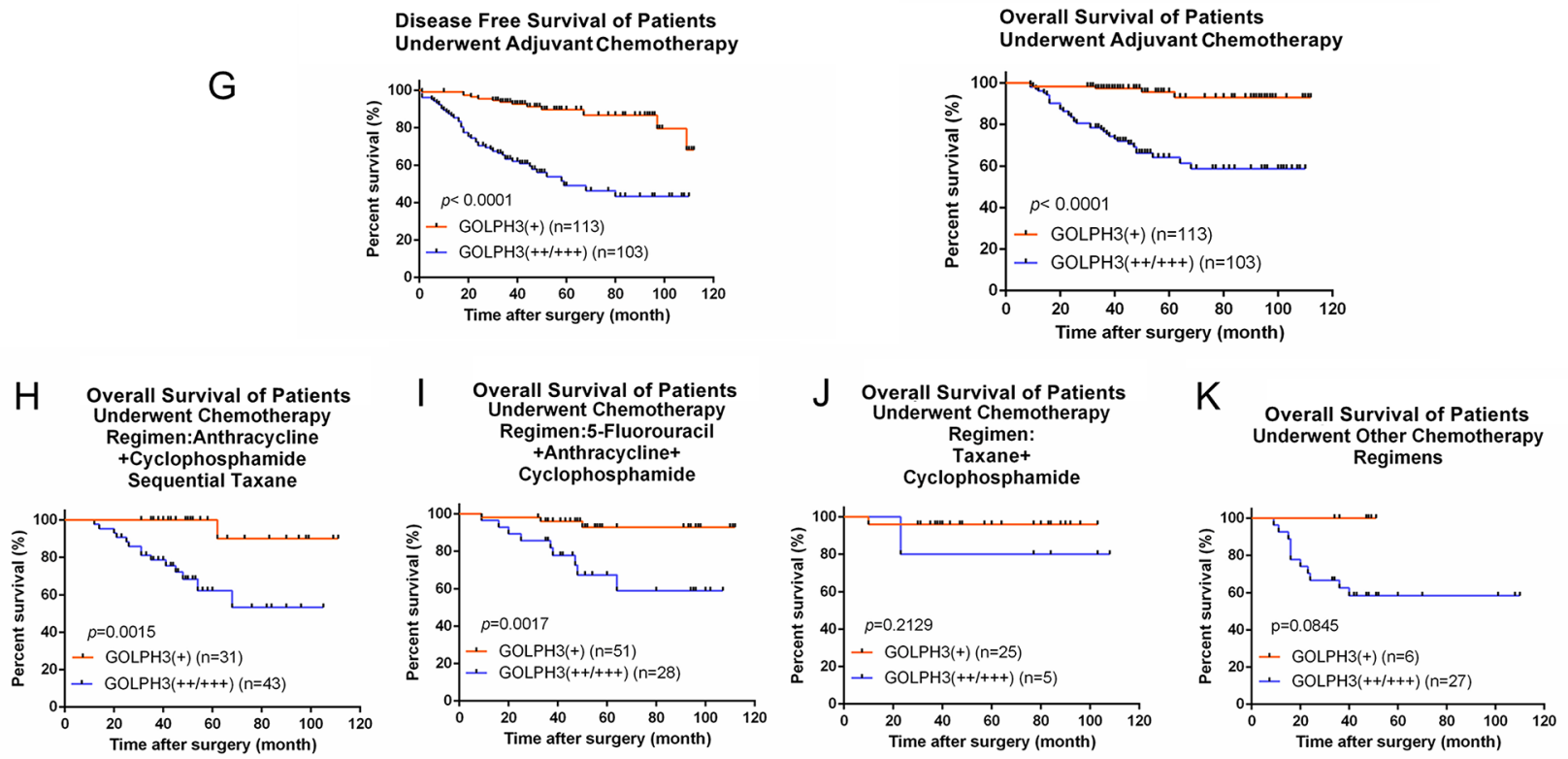

Figure 3: Disease-free survival and overall survival of breast cancer patients with different GOLPH3 expression levels. (A) DFS and OS were analyzed by the Kaplan-Meier method for breast cancer patients with low GOLPH3 expression (GOLPH3+) $(n=129)$ compared to those with high GOLPH3 expression $(\mathrm{GOLPH} 3++/+++)(n=120)$. (B) DFS and OS were analyzed in patients with luminal A breast cancer. (C) DFS and OS were analyzed in patients with luminal B1 breast cancer. (D) DFS and OS were analyzed in patients with luminal B2 breast cancer. (E) DFS and OS were analyzed in patients with HER-2 positive breast cancer. (F) DFS and OS were analyzed in patients with TNB breast cancer. (G) DFS and OS of patients received adjuvant chemotherapy. (H) OS of patients treated with anthracycline+cyclophosphamide sequential taxane. (I) OS of patients treated with 5-fluorouracil +anthracycline+cyclophosphamide. (J) OS of patients treated with taxane+cyclophosphamide. (K) OS of patients treated with other chemotherapy regimens. 
Table 1: Association between GOLPH3 expression and the clinicopathological features of 249 breast cancer patients

\begin{tabular}{|c|c|c|c|c|}
\hline \multirow[t]{2}{*}{ Variables } & \multirow[t]{2}{*}{ Total $(n=249)$} & \multicolumn{2}{|c|}{ Expression of GOLPH3 } & \multirow[t]{2}{*}{ P-value } \\
\hline & & Low $(n=129)$ & High $(n=120)$ & \\
\hline Age & & & & 0.080 \\
\hline$<40$ & 34 & 21 & 13 & \\
\hline $40 \leq \mathrm{Age}<50$ & 90 & 37 & 53 & \\
\hline $50 \leq \mathrm{Age}<60$ & 80 & 45 & 35 & \\
\hline$\geq 60$ & 45 & 26 & 19 & \\
\hline$T$ classification & & & & 0.033 \\
\hline $\mathrm{T} 1$ & 21 & 16 & 5 & \\
\hline $\mathrm{T} 2$ & 183 & 95 & 88 & \\
\hline $\mathrm{T} 3$ & 28 & 13 & 15 & \\
\hline $\mathrm{T} 4$ & 17 & 5 & 12 & \\
\hline $\mathbf{N}$ classification & & & & $<0.001$ \\
\hline N0 & 94 & 87 & 7 & \\
\hline N1 & 69 & 38 & 31 & \\
\hline $\mathrm{N} 2$ & 56 & 4 & 52 & \\
\hline N3 & 30 & 0 & 30 & \\
\hline M classification & & & & $<0.001$ \\
\hline M0 & 238 & 129 & 109 & \\
\hline M1 & 11 & 0 & 11 & \\
\hline Molecular subtype & & & & 0.012 \\
\hline Luminal A & 46 & 25 & 21 & \\
\hline Luminal B1 & 66 & 39 & 27 & \\
\hline Luminal B2 & 73 & 44 & 29 & \\
\hline Her-2 positive & 41 & 13 & 28 & \\
\hline Triple negative & 23 & 8 & 15 & \\
\hline Surgery type & & & & $<0.001$ \\
\hline Simple mastectomy & 44 & 41 & 3 & \\
\hline $\begin{array}{l}\text { Modified radical } \\
\text { mastectomy }\end{array}$ & 179 & 68 & 111 & \\
\hline $\begin{array}{l}\text { Breast conserving } \\
\text { surgery }\end{array}$ & 18 & 17 & 1 & \\
\hline Section resection & 8 & 3 & 5 & \\
\hline
\end{tabular}

Note. Luminal A: ER (+) and PR (+), PR $\geq 20 \%$, Her-2 (-), Ki-67<14\%; Luminal B1: ER (+), Her-2 (-), Ki-67 $\geq 14 \%$ or PR $<20 \%$; Luminal B2: ER $(+)$, Her-2 (+), Ki- $67 \geq 14 \%$ or PR $<20 \%$; Her-2 positive: ER (-) and PR (-), Her-2 (+); Triple negative: ER (-) and PR (-), Her-2 (-). The results was corrected to three decimal places.

indicated a high risk of recurrence $(\mathrm{p}=0.027)$ (Table 6) but no statistical difference in OS ( $\mathrm{p}=0.0845)$ (Figure $3 \mathrm{~K})$.

\section{DISCUSSION}

In this study, the clinical significance of GOLPH3 in breast cancer was explored. GOLPH3 was found to be highly expressed in breast cancer tissue and cell lines. GOLPH3 silencing inhibited cell migration, invasion, and proliferation, and promoted apoptosis of breast cancer cells. Importantly, patients with GOLPH3 overexpression had poor DFS and OS, and GOLPH3 expression was associated with clinicopathologic factors such as age, TNM classification, and molecular subtype but did 
Table 2: Kaplan-Meier survival analysis of GOLPH3 expression in breast cancer patients

\begin{tabular}{|c|c|c|c|c|c|c|c|}
\hline \multirow[t]{2}{*}{ Variables } & \multirow{2}{*}{$\begin{array}{c}\text { Total } \\
(n=249)\end{array}$} & \multicolumn{2}{|c|}{ DFS } & \multirow[t]{2}{*}{ P value } & \multicolumn{2}{|c|}{ OS } & \multirow[t]{2}{*}{$P$ value } \\
\hline & & $\begin{array}{c}\text { Mean } \\
\text { (month) }\end{array}$ & $\begin{array}{l}\text { Median } \\
\text { (month) } \\
\end{array}$ & & $\begin{array}{c}\text { Mean } \\
\text { (month) }\end{array}$ & $\begin{array}{l}\text { Median } \\
\text { (month) }\end{array}$ & \\
\hline Age & & & & 0.145 & & & 0.228 \\
\hline$<40$ & 34 & 90.97 & NA & & 89.73 & NA & \\
\hline $40 \leq \mathrm{Age}<50$ & 90 & 84.28 & NA & & 95.07 & NA & \\
\hline $51 \leq$ Age $<60$ & 80 & 82.23 & 109.00 & & 89.75 & NA & \\
\hline$\geq 60$ & 45 & 80.70 & NA & & 79.05 & NA & \\
\hline T classification & & & & 0.000 & & & 0.023 \\
\hline $\mathrm{T} 1$ & 21 & 96.70 & NA & & 98.55 & NA & \\
\hline $\mathrm{T} 2$ & 183 & 88.43 & NA & & 93.84 & NA & \\
\hline $\mathrm{T} 3$ & 28 & 55.59 & 46.00 & & 82.44 & NA & \\
\hline $\mathrm{T} 4$ & 17 & 36.60 & 40.00 & & 43.42 & NA & \\
\hline $\mathbf{N}$ classification & & & & 0.000 & & & 0.000 \\
\hline No & 94 & 110.86 & NA & & 109.82 & NA & \\
\hline N1 & 69 & 85.13 & 109.00 & & 99.38 & NA & \\
\hline N2 & 56 & 55.87 & 52.00 & & 72.30 & 68.00 & \\
\hline N3 & 30 & 35.14 & 30.00 & & 41.30 & 35.00 & \\
\hline M classification & & & & 0.000 & & & 0.005 \\
\hline M0 & 238 & 85.43 & NA & & 93.28 & NA & \\
\hline M1 & 11 & 34.80 & 40.00 & & 49.64 & NA & \\
\hline $\begin{array}{l}\text { Molecular } \\
\text { subtype }\end{array}$ & & & & 0.046 & & & 0.029 \\
\hline Luminal A & 46 & 94.51 & NA & & 98.41 & NA & \\
\hline Luminal B1 & 66 & 84.70 & NA & & 94.55 & NA & \\
\hline Luminal B2 & 73 & 86.98 & NA & & 88.34 & NA & \\
\hline Her-2 positive & 41 & 73.79 & NA & & 88.13 & NA & \\
\hline Triple negative & 23 & 78.57 & NA & & 80.89 & NA & \\
\hline Surgery type & & & & 0.158 & & & 0.225 \\
\hline $\begin{array}{l}\text { Simple } \\
\text { mastectomy }\end{array}$ & 44 & 99.39 & NA & & 101.02 & NA & \\
\hline $\begin{array}{l}\text { Modified radical } \\
\text { mastectomy }\end{array}$ & 179 & 76.88 & 109 & & 87.99 & NA & \\
\hline $\begin{array}{l}\text { Breast conserving } \\
\text { surgery }\end{array}$ & 18 & 106.21 & NA & & 107.14 & NA & \\
\hline Section resection & 8 & 70.00 & NA & & 73.05 & NA & \\
\hline $\begin{array}{l}\text { GOLPH3 } \\
\text { expression }\end{array}$ & & & & 0.000 & & & 0.000 \\
\hline Low & 129 & 101.61 & NA & & 107.22 & NA & \\
\hline High & 120 & 67.125 & 93.00 & & 74.86 & NA & \\
\hline
\end{tabular}

Note. Luminal A: ER (+) and PR (+), PR $\geq 20 \%$, Her-2 (-), Ki-67<14\%; Luminal B1: ER (+), Her-2 (-), Ki-67 $\geq 14 \%$ or PR $<20 \%$; Luminal B2: ER (+), Her-2 (+), Ki-67 $\geq 14 \%$ or PR $<20 \%$; Her-2 positive: ER (-) and PR (-), Her-2 (+); Triple negative: ER (-) and PR (-), Her-2 (-). The results was corrected to three decimal places.

Abbreviations: DFS, disease free survival; OS, overall survival; NA, none detected. 
Table 3: Cox multivariate analysis of disease free survival and overall survival

\begin{tabular}{|c|c|c|c|c|c|c|}
\hline \multirow[t]{2}{*}{ Variables } & \multicolumn{3}{|c|}{ Disease free survival } & \multicolumn{3}{|c|}{ Overall survival } \\
\hline & Hazard ratio & $\begin{array}{c}95 \% \\
\text { confidence } \\
\text { interval }\end{array}$ & P-value & Hazard ratio & $\begin{array}{c}95 \% \\
\text { confidence } \\
\text { interval }\end{array}$ & P-value \\
\hline Age & 1.022 & $0.999-1.046$ & 0.061 & 1.105 & $0.987-1.043$ & 0.305 \\
\hline T classification & 1.432 & $1.026-1.998$ & 0.035 & 1.036 & $0.680-1.576$ & 0.870 \\
\hline N classification & 2.766 & $1.859-4.114$ & 0.000 & 2.498 & $1.570-3.975$ & 0.000 \\
\hline M classification & 1.780 & $0.770-4.111$ & 0.177 & 1.645 & $0.624-4.335$ & 0.314 \\
\hline $\begin{array}{l}\text { Molecular } \\
\text { subtype }\end{array}$ & 1.333 & $1.087-1.635$ & 0.006 & 1.331 & $1.054-1.681$ & 0.016 \\
\hline Surgery type & 1.006 & $0.625-1.617$ & 0.982 & 0.955 & $0.508-1.795$ & 0.886 \\
\hline $\begin{array}{l}\text { GOLPH3 } \\
\text { expression }\end{array}$ & 1.897 & $1.536-3.913$ & 0.003 & 2.013 & $1.442-3.209$ & 0.002 \\
\hline
\end{tabular}

Note. The results was corrected to three decimal places.

Table 4: Correlation between GOLPH3 expression and effect of neoadjuvant chemotherapy

\begin{tabular}{lcccc}
\hline GOLPH3 expression & Total (n) & PR (n) & SD (n) & P-value \\
\hline GOLPH3 + & 18 & 15 & 3 & 0.021 \\
GOLPH3 ++/+++ & 36 & 18 & 18 & \\
Total & 54 & 33 & 21 & \\
\hline
\end{tabular}

Abbreviations: PR, partial response; SD, stable disease.

Table 5: Correlation between GOLPH3 expression and effect of different neoadjuvant regimens

\begin{tabular}{|c|c|c|c|c|c|}
\hline Neoadjuvant regimen & $\begin{array}{c}\text { GOLPH3 } \\
\text { expression }\end{array}$ & Total (n) & PR (n) & SD (n) & P-value \\
\hline \multirow{2}{*}{$\begin{array}{l}\text { Anthracycline + taxane } \\
+ \text { cyclophosphamide } \\
(\mathrm{n}=22)\end{array}$} & GOLPH3 + & 8 & 7 & 1 & 0.05 \\
\hline & GOLPH3 ++/+++ & 14 & 6 & 8 & \\
\hline \multirow{2}{*}{$\begin{array}{l}\text { 5-fluorouracil }+ \\
\text { anthracycline }+ \\
\text { cyclophosphamide } \\
(\mathrm{n}=20)\end{array}$} & GOLPH3 + & 9 & 7 & 2 & 0.492 \\
\hline & GOLPH3 ++/+++ & 11 & 7 & 4 & \\
\hline \multirow[t]{2}{*}{ Others $(n=12)$} & GOLPH3 + & 1 & 1 & 0 & 0.296 \\
\hline & GOLPH3 ++/+++ & 11 & 5 & 6 & \\
\hline
\end{tabular}

Abbreviations: PR, partial response; SD, stable disease.

not correlate with surgery type. Furthermore, patients with high GOLPH3 expression showed resistance to chemotherapy.

Compared with adjacent noncancerous tissue and fibroadenoma samples, GOLPH3 was significantly upregulated in breast cancer tissue. This finding is in accordance with a previous report [26]. Interestingly, GOLPH3 is also elevated in lung [18][23], prostate [21], ovarian epithelial [20], hepatoma [22], and rectal cancers [25], implying that GOLPH3 plays a role in the occurrence 
Table 6: Recurrence between GOLPH3 expression and different chemotherapy regimens after surgery

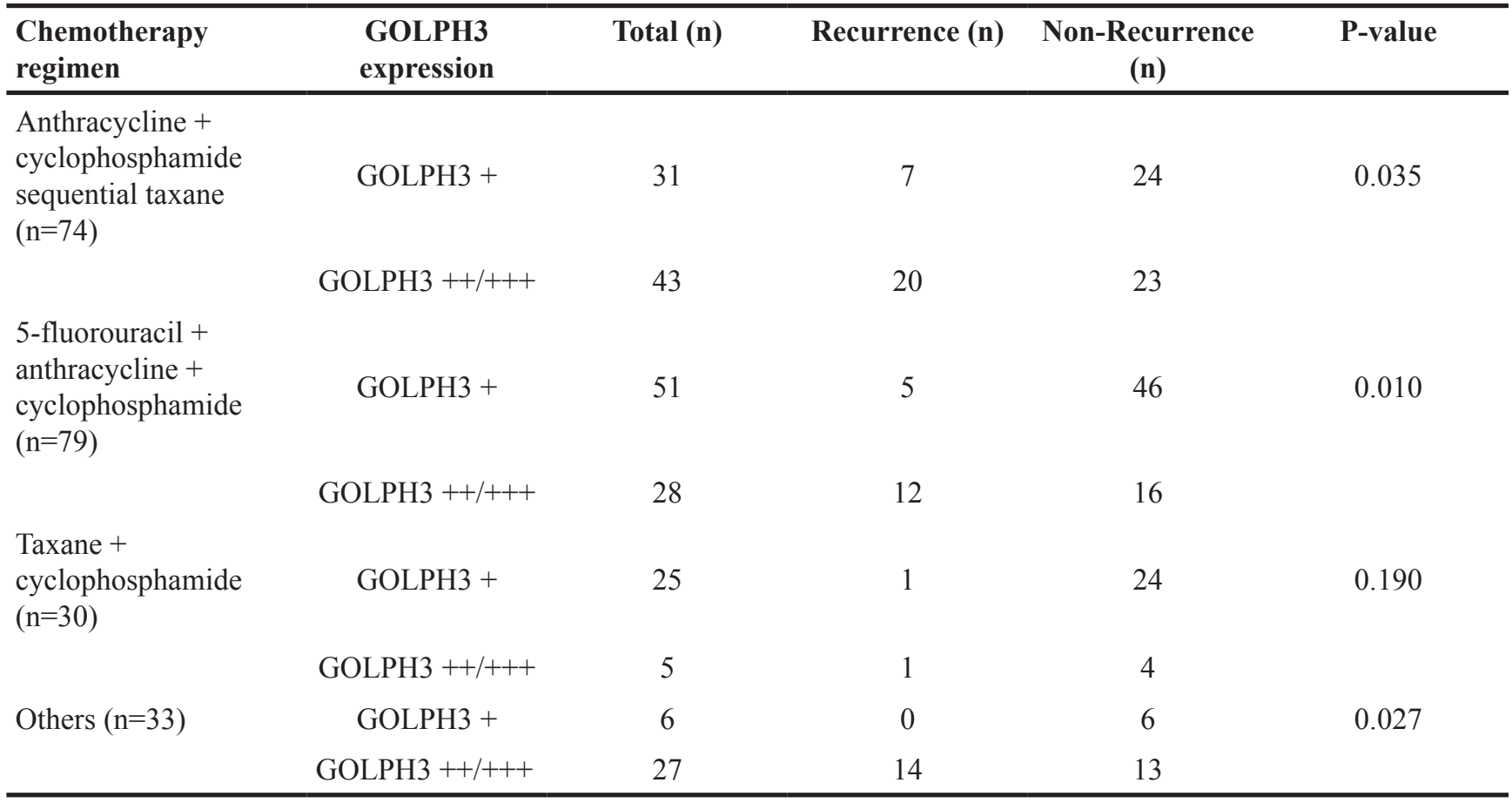

or development of tumors and may have potential for use in cancer diagnosis. A malignant tumor is regarded as a neoplasm with aggressive, migration and rare apoptosis [30]. The migration and invasion of cancer cells comprise a complex multi-step process including reorganization of the cytoskeleton, degradation of the extracellular matrix, adhesion, and de-adhesion [27-29]. In this study, downregulation of GOLPH3 siRNA not only significantly reduced the migration, invasion, and proliferation of two breast cancer cell lines but also promoted cell apoptosis, indicating that GOLPH3 affects breast cancer development. Similar to breast cancer, GOLPH3 also plays a role in other cancers such as lung [18, 23], bladder [19], and renal cell cancers [25]. Thus, GOLPH3 is not merely a diagnostic marker for breast cancer but may also have potential as a significant therapeutic target just like trastuzumab target human epidermal growth factor receptor 2.

Our investigation also revealed that high GOLPH3 expression affected the DFS and OS in breast cancer patients. Similar results were found for renal cell carcinoma [24, 25]. Xue et al. [24] noticed that high GOLPH3 expression correlated with poor OS in 218 renal cell carcinoma patients [24], and Zhu et al. [25] found that GOLPH3 overexpression correlated with a worse DFS and OS in 77 rectal carcinoma patients compared with 70 patients with low levels of GOLPH3 expression. Meanwhile, Zeng et al. [26] reported that the overexpression of GOLPH3 was associated with poor OS in breast cancer. Our results not only confirmed that patients with high GOLPH3 expression had worse OS but also revealed that high GOLPH3 expression correlated with worse DFS in breast cancer.
We presented a systematic study of the correlation between GOLPH3 and clinical pathological characteristics including age, TNM classification, and molecular subtype. This is the first study to evaluate how GOLPH3 expression influences the survival of breast cancer patients in different age groups. We demonstrated that the risk of recurrence increases with increasing age in patients with high GOLPH3 expression; thus, GOLPH3 may be a suitable predictor of the survival of breast cancer patients $>40$ years of age. We also performed a comprehensive investigation between GOLPH3 and TNM classification and found that high GOLPH3 expression led to a worse prognosis in breast cancer patients with advanced tumor invasion depth and lymphatic metastasis. Xue et al. [24] investigated the association of GOLPH3 with tumor invasion depth in renal cell carcinoma and showed that poor OS was observed in the high GOLPH3 expression group. Similar results were observed in our study in patients with high GOLPH3 expression with advanced lymphatic metastasis. However, Xue et al. [24] did not show the correlation between GOLPH3 and other clinical features such as age, molecular subtype, or surgery type. Importantly, we found that high GOLPH3 expression led to a poor DFS and OS in all molecular subtypes, suggesting that GOLPH3 may be an important therapeutic target in breast cancer. In addition, surgery type had no influence on the survival of patients with high GOLPH3 expression.

Systemic chemotherapy, including neoadjuvant chemotherapy and adjuvant chemotherapy, is a very important treatment strategy for breast cancer patients [31-37]. To date, no studies have investigated the association between GOLPH3 expression and neoadjuvant 
chemotherapy in breast cancer. Our study showed that in breast cancer patients, GOLPH3 overexpression was associated with resistance to neoadjuvant chemotherapy, especially to the most frequently used regimen of ant hracycline+taxane+cyclophosphamide, although these results were based on data from a small number of patients. This result is in agreement with a previous report that showed that GOLPH3 overexpression leads to failure of neoadjuvant chemotherapy in locally advanced rectal cancer [25]. For patients who received adjuvant chemotherapies after surgery, our results demonstrated that patients with high GOLPH3 expression had a higher risk of disease recurrence and death if the chemotherapy regimen was the anthracycline+cyclophosphamide sequential taxane regimen or 5-fluorouracil+anthracyclin e+cyclophosphamide. However, in patients who received the taxane+cyclophosphamide regimen, GOLPH3 expression did not affect DFS and OS. For patients who received the taxane+cyclophosphamide regimen, their disease was not so severe that GOLPH3 expression impacted survival. Together, these data suggest that GOLPH3 overexpression may attenuate the effects of anthracycline or 5-fluorouracil. Interestingly, it has been reported that high GOLPH3 expression is associated with favorable prognosis in colorectal cancer patients treated with 5-fluorouracil adjuvant chemotherapy [38]. This contradictory result may be attributed to differences between breast cancer and colorectal cancer.

In summary, our results suggest that GOLPH3 is a very important oncogene that plays a significant role in breast cancer. High GOLPH3 expression usually suggests poor survival and resistance to chemotherapy in breast cancer. Therefore, GOLPH3 has high prospective value in diagnosis and may serve as a clinical indicator and prognostic marker for patients. However, due to the limitations of the current study, further investigations on the clinical use of GOLPH3 are required to confirm these data.

\section{MATERIALS AND METHODS}

\section{Patient information, follow up, and tissue samples}

A total of 249 breast cancer tissue samples, 72 adjacent noncancerous tissue (ANT), and 20 fibroadenoma samples were obtained from patients who underwent surgical treatment in Tumor Hospital of Guangxi Medical University from 2007 to 2013 . We separated the tissue samples into two parts: one part was immediately frozen and stored at $-80^{\circ} \mathrm{C}$ in the Tumor Tissue Bank of Tumor Hospital of Guangxi Medical University for gene expression analysis, and the other part was fixed in formalin and embedded in paraffin for immunohistochemical analysis. All slides were blindly reviewed by two pathologists and a consensus diagnosis was reached. Pathologic classification and stage was determined according to the American Joint Committee on Cancer criteria. Molecular subtypes were determined according to the 2013 St Gallen criteria. Patients were followed up from the time of surgery to death or last contact. The protocols of the study were approved by Ethnics Committees of Tumor Hospital of Guangxi Medical University.

\section{Cell culture, siRNA for GOLPH3, and transfection}

The breast cancer cell lines (MDA-MB-231 and MCF-7) were purchased from Cell Bank of the Chinese Academy of Science (Shanghai, China). The cells were cultured in Dulbecco's Modified Eagle Medium with $15 \%$ fetal bovine serum, $0.5 \%$ streptomycin, and $0.5 \%$ penicillin (Life Technologies, Washington DC, USA) at $37^{\circ} \mathrm{C}$ and $5 \% \mathrm{CO} 2$. GOLPH3 siRNA was designed by Gene Pharma (Shanghai, China) to knockdown GOLPH3 expression. The sequence of siRNA was 5'GUUA AGAAAUGUACGGGAATT-3'. A scrambled siRNA (scram-siRNA) was used as a negative control. The sequence of the scram-siRNA was 5'-UUCUC CGAACGUGUCACGUTT-3'. The breast cancer cell lines were transfected with either GOLPH3-siRNA or scramsiRNA according to the manufacturer's protocol. Fortyeight hours after transfection, qPCR assays and Western blotting analyses were performed to analyze GOLPH3 mRNA and protein expression.

\section{Immunohistochemistry}

GOLPH3 antibodies (1:150 dilution; ab91492, Abcam, Cambridge, MA, USA) were chosen for immunohistochemistry. Sections were incubated for $1 \mathrm{~h}$ at $60^{\circ} \mathrm{C}$, dewaxed for $40 \mathrm{~min}$ in dimethylbenzene, and rehydrated. After washing in phosphate-buffered saline (PBS) solution, the sections were blocked in 5\% normal goat serum for $30 \mathrm{~min}$. To inhibit endogenous peroxidase activity, the sections were treated with $0.5 \%$ hydrogen peroxide methanol for $30 \mathrm{~min}$. Primary antibodies were added dropwise to the sections, after which the sections were incubated overnight at $4^{\circ} \mathrm{C}$. Next, sections were rewarmed for $30 \mathrm{~min}$ at room temperature, washed three times with PBS for $5 \mathrm{~min}$, and incubated with the appropriate secondary antibodies (1:200 dilution; ab186696, Abcam) for $30 \mathrm{~min}$ at $37^{\circ} \mathrm{C}$. This was followed by another three 5-min wash with PBS, after which $0.05 \%$ DAB was added for visualization of immunoreactivity. Sections were dehydrated in a series of $100 \%, 95 \%, 80 \%$, and $75 \%$ graded ethanol and counterstained with hematoxylin. GOLPH3 expression was assessed by evaluating the proportion and intensity of positively stained carcinoma cells. A score was assigned to represent the estimated percentage of positively stained carcinoma cells as follows: 0 : none, $1: \leq 50 \%, 2: 50$ $75 \%$, and $3: \geq 75 \%$. An intensity score was assigned to 
represent the average estimated intensity of staining in positive carcinoma cells as follows: 0 : none, 1: weak, 2: intermediate, and 3: strong. The proportion score and intensity score were multiplied to obtain a total score ranging from 0 to 9 . The immunohistochemistry results were classified based on total scores with $0-4$ classified as + , 5-6 indicating ++ , and 7-9 indicating $+++[19]$.

\section{Western blotting}

Protein was extracted by RIPA buffer (BOSTER, Wuhan, China) containing $1 \mathrm{mM} / \mathrm{L}$ PMSF (BOSTER, Wuhan, China). The concentration of total protein in each sample was measured by the BCA protein assay kit (BOSTER, Wuhan, China), after which 10\% SDS-PAGE gels were used to separate $50 \mu \mathrm{g}$ protein. Then the proteins were electrophoretically transferred to polyvinylidene fluoride membranes (Millipore, MA, USA). After blocking in Tris-buffered saline with Tween $20(10 \mathrm{mM} / \mathrm{L}$ Tris-HCL pH 7.5, $150 \mathrm{mM} / \mathrm{L} \mathrm{NaCl}$, and $0.05 \%$ Tween-20) containing $5 \%$ non-fat milk for $1 \mathrm{~h}$, the membranes were incubated overnight at $4{ }^{\circ} \mathrm{C}$ with primary anti-GOLPH3 monoclonal antibody (1:1000 dilution; ab91492, Abcam) and $\alpha$-tubulin (1:6000 dilution; ab7291, Abcam). Then the membranes were washed three times with TBST for $10 \mathrm{~min}$ and probed with secondary antibody (1:10000 dilution, ab186696, Abcam) for $1 \mathrm{~h}$ at room temperature. Signals were visualized with enhanced chemiluminescence solution (BOSTER) by exposure to film.

\section{RNA extraction, RT-PCR, and qPCR}

Total RNA from both cell lines and tissue samples was extracted using the TaKaRa MiniBEST Universal RNA Extraction Kit (TaKaRa, Shiga, Japan) according to the manufacturer's instructions. The RNeasy Mini Kit (TaKaRa) was used for further purification. cDNA was both reverse transcribed using the PrimeScript ${ }^{\text {TMRT }}$ reagent Kit (TaKaRa), after which the cDNA underwent a $42^{\circ} \mathrm{C} 2 \mathrm{~min}$ reaction. Then $10 \mu \mathrm{L}$ DNA erase compound was mixed with PrimeScript RT Enzyme Mix I, RT Primer Mix, 5× PrimeScript Buffer 2 (for Real Time) and RNase Free $\mathrm{dH}_{2} \mathrm{O}$ in a $20 \mu \mathrm{L}$ reaction. Then a $\mathrm{PCR}$ reaction at $37^{\circ} \mathrm{C}$ for $15 \mathrm{~min}$, and at $85^{\circ} \mathrm{C} 5 \mathrm{~s}$ was performed. The cDNA was preserved at $4^{\circ} \mathrm{C}$ for $\mathrm{qPCR}$. GOLPH3 forward and reverse primers were synthesized. The GOLPH3 primers were as follows: 5'- GGGCGACT CCAAGGAAAC -3' for forward and 5' - CAGCCACGTAA TCCAGATGAT -3' for reverse primers. GAPDH was used as the internal control with specific primers: 5'-GCACCGTCAAGGCTGAGAAC-3' for forward and 5'-TGGTGAAGACGCCAGTGGA-3' for reverse. The reaction system contained SYBR ${ }^{2}$ Premix Ex Taq II (Tli RNaseH Plus, PCR forward primer, PCR reverse primer, ROX Reference Dye $(50 \times), \mathrm{dH}_{2} \mathrm{O}$, and cDNA templates. Gene and species-specific primer/internal reference were performed on the Applied Biosystems StepOne Plus Realtime PCR system at $95^{\circ} \mathrm{C}$ for $30 \mathrm{~s}$ for 1 cycle and at $95^{\circ} \mathrm{C}$ for $3 \mathrm{~s}$ and then at $60^{\circ} \mathrm{C}$ for $30 \mathrm{~s}$ for 40 cycles. The data were analyzed using the comparative threshold cycle $\left(2^{-\Delta \Delta \mathrm{CT}}\right)$ method.

\section{Migration and invasion assay}

A total of $2 \times 10^{5} \mathrm{MCF}-7$ cells/well and $1 \times 10^{4} \mathrm{MDA}-$ MB-231 cells/well were resuspended in culture medium without serum and seeded. For the migration assay, transfected and control cells were plated in the upper chamber without matrigel. The same concentration of cells was plated on an $8 \mu \mathrm{m}$ pore coated with $60 \mu \mathrm{L}$ matrigel for the invasion assay. Culture medium that contained $10 \%$ serum was used in the lower chamber. After $24 \mathrm{~h}$, cells that did not invade or migrate were removed. The migrated and invaded cells were fixed in $4 \%$ polysorbate, dyed with the Giemsa stain, quantified, and photographed.

\section{CCK-8 assay}

Cell proliferation was analyzed by the CCK- 8 assay. Briefly, $5 \times 10^{4}$ cells $/ \mathrm{mL}$ and $100 \mu \mathrm{L}$ suspension were added to a 96 -well plate. Cells were continuously cultured at $37^{\circ} \mathrm{C}$ for $4 \mathrm{~h}$. Then $10 \mu \mathrm{L} \mathrm{CCK}-8$ solution (BestBio, Shanghai, China) was added to each well at 24, 48 , and 72 $\mathrm{h}$ after culturing followed by incubation at $37^{\circ} \mathrm{C}$ for $4 \mathrm{~h}$. The optical density of the suspensions was determined by absorbance at $450 \mathrm{~nm}$.

\section{Flow cytometer analysis}

Flow cytometry was used for cell apoptosis analysis. Cells were harvested $48 \mathrm{~h}$ after transfection, and washed twice with ice-cold PBS. $1 \times$ staining buffer was mixed to adjust the cell concentration to $1 \times 10^{6}$ cells $/ \mathrm{mL}$. Then $400 \mu \mathrm{L}$ of $1 \times$ binding buffer was mixed and $100 \mu \mathrm{L}$ cell suspension was incubated with $3 \mu \mathrm{L}$ propidium iodide (PI) and $5 \mu \mathrm{L}$ Annexin V-FITC for $15 \mathrm{~min}$ in the dark. For cell cycle analysis, cells were fixed in $70 \%$ ethanol and stored at $-20^{\circ} \mathrm{C}$ overnight. The suspension was stained with PI at $4^{\circ} \mathrm{C}$ in the dark. The apoptosis and cell cycle of cells were analyzed with the BD Accuri C6 flow cytometry system (BD Biosciences, San Jose, CA, USA).

\section{Chemotherapy treatment}

A total of 54 patients in the cohort of 249 patients received neoadjuvant chemotherapy before surgery. Patients who received neoadjuvant chemotherapy strategies were classified into three subgroups. The first subgroup comprised 22 patients who received the anthracycline + taxane + cycloph osphamide regimen. Of these 22 patients, 12 underwent two to four cycles of the TAC regimen (i.e., docetaxel $75 \mathrm{mg}$ / $\mathrm{m}^{2}$, pirarubicin $60 \mathrm{mg} / \mathrm{m}^{2}$, and cyclophosphamide $600 \mathrm{mg} /$ $\mathrm{m}^{2}$ iv on day 1 , every 3 weeks). The remaining 10 patients 
received two to four cycles of the TEC regimen (docetaxel $75 \mathrm{mg} / \mathrm{m}^{2}$, epirubicin $100 \mathrm{mg} / \mathrm{m}^{2}$, and cyclophosphamide $600 \mathrm{mg} / \mathrm{m}^{2}$ iv on day 1 , every 3 weeks). The second subgroup comprised 20 patients who received two to five cycles of the 5-fluorouracil+anthracycline+cyclophosp hamide regimen. Of these 20 patients, 7 received two to four cycles of the FAC regimen (i.e., 5-fluorouracil 600 $\mathrm{mg} / \mathrm{m}^{2}$, pirarubicin $60 \mathrm{mg} / \mathrm{m}^{2}$, and cyclophosphamide 600 $\mathrm{mg} / \mathrm{m}^{2}$ iv on day 1 , every 3 weeks). The remaining 13 patients received two to five cycles of the FEC regimen (i.e., 5-fluorouracil $600 \mathrm{mg} / \mathrm{m}^{2}$, epirubicin $100 \mathrm{mg} / \mathrm{m}^{2}$, and cyclophosphamide $600 \mathrm{mg} / \mathrm{m}^{2}$ iv on day 1 , every 3 weeks) The third subgroup contained 12 patients who received other neoadjuvant chemotherapy regimens. A total of 216 patients received adjuvant chemotherapy after surgery. We divided the patients into four treatment groups: (1) 74 patients were treated with anthracycline + cyclophosphamide sequential taxane; 55 patients received $\mathrm{AC} \rightarrow \mathrm{T}$ ( 4 cycles of pirarubicin $60 \mathrm{mg} / \mathrm{m}^{2}$ iv on day 1 , cyclophosphamide $600 \mathrm{mg} / \mathrm{m}^{2}$ iv on day 1 , every 2 or 3 weeks $\rightarrow 4$ cycles of docetaxel $75 \mathrm{mg} /$ $\mathrm{m}^{2}$ iv on day 1 , every 2 or 3 weeks). 19 patients received $\mathrm{EC} \rightarrow \mathrm{T}$ (four cycles of epirubicin $100 \mathrm{mg} / \mathrm{m}^{2}$ iv on day 1 , cyclophosphamide $600 \mathrm{mg} / \mathrm{m}^{2}$ iv on day 1 , every 2 or 3 weeks $\rightarrow$ four cycles of docetaxel $75 \mathrm{mg} / \mathrm{m}^{2}$ iv on day 1, every 2 or 3 weeks). (2) 79 patients received the 5 -flu orouracil+anthracycline+cyclophosphamide regimen, as outlined above. (3) 30 patients underwent four to six cycles of the taxane+cyclophosphamide regimen (docetaxel $75 \mathrm{mg}$ / $\mathrm{m}^{2}$ iv on day 1 , cyclophosphamide $600 \mathrm{mg} / \mathrm{m}^{2}$ iv on day 1, every 3 weeks). (4) 33 patients received other adjuvant chemotherapy regimens.

\section{Statistical analysis}

All statistical analyses were performed with SPSS Statistics 21.0 (IBM, Chicago, IL, USA) and Graphpad Prism 6.0. Comparisons in continuous outcomes between groups for statistical significance were carried out with a two-tailed paired Student $t$-test. The relationship between GOLPH3 expression and clinicopathological characteristics was evaluated by the chi-squared test, and the Fisher's exact test was used when the unit was less than six. OS and DFS were assessed by the KaplanMeier method and compared by the log-rank test. COX regression models were used for survival data. $\mathrm{P}$ values less than 0.05 were considered statistically significant. ${ }^{*} P$ $<0.05,{ }^{* *} P<0.01,{ }^{* * *} P<0.001$, relative to the control.

\section{CONFLICTS OF INTEREST}

The authors have no conflicts of interest to declare.

\section{FUNDING}

This work was supported by the National Natural Science Foundation of China (Grant Nos. 81402306 and
81360312), the Guangxi Natural Science Foundation Program (Grant No. 2014GXNSFBA118158), the Science and Technology Research Project of the Guangxi Colleges and Universities (Grant No. YB2014080), and the Youth Science Foundation of Guangxi Medical University (Grant No. GXMUYSF201209).

\section{REFERENCES}

1. Al-Hajj M, Wicha MS, Benito-Hernandez A, Morrison SJ, Clarke MF. Prospective identification of tumorigenic breast cancer cells. Proc Natl Acad Sci U S A. 2003; 100: 3983-8. http://dx.doi.org/10.1073/pnas.0530291100.

2. Benson JR, Jatoi I. The global breast cancer burden. Future Oncol. 2012; 8: 697-702. http://dx.doi.org/10.2217/ fon.12.61.

3. Welch HG, Prorok PC, O'Malley AJ, Kramer BS. BreastCancer Tumor Size, Overdiagnosis, Mammography Screening Effectiveness. N Engl J Med. 2016; 375: 143847. http://dx.doi.org/10.1186/1479-5876-12-15.

4. Torre LA, Sauer AM, Chen MS, Kagawa-Singer M, Jemal A, Siegel RL. Cancer statistics for Asian Americans, Native Hawaiians, and Pacific Islanders, 2016: Converging incidence in males and females. CA Cancer J Clin. 2016; 66: 182-202. http://dx.doi.org/10.3322/caac.21335.

5. Baumann K. DNA damage: Dispersing Golgi. Nat Rev Mol Cell Biol. 2014; 15: 153. http://dx.doi.org/10.1038/ nrm3762.

6. Rizzo R, Parashuraman S, D'Angelo G, Luini A. GOLPH3 and oncogenesis: What is the molecular link. Tissue Cell. 2016; 49: 170-174. http://dx.doi.org/10.1016/j. tice.2016.06.008.

7. Tan X, Banerjee P, Guo HF, Ireland S, Pankova D, Ahn YH, Nikolaidis IM, Liu X, Zhao Y, Xue Y, Burns AR, Roybal J, Gibbons DL, et al. Epithelial-to-mesenchymal transition drives a pro-metastatic Golgi compaction process through scaffolding protein PAQR11. J Clin Invest. 2017; 127: 11731. http://dx.doi.org/10.1172/JCI88736.

8. Dippold HC, Ng MM, Farber-Katz SE, Lee SK, Kerr ML, Peterman MC, Sim R, Wiharto PA, Galbraith KA, Madhavarapu S, Fuchs GJ, Meerloo T, Farquhar MG, et al. GOLPH3 bridges phosphatidylinositol-4- phosphate and actomyosin to stretch and shape the Golgi to promote budding. Cell. 2009; 139: 337-51. http://dx.doi. org/10.1016/j.cell.2009.07.052.

9. Nakashima-Kamimura N, Asoh S, Ishibashi Y, Mukai Y, Shidara Y, Oda H, Munakata K, Goto Y, Ohta S. MIDAS/GPP34, a nuclear gene product, regulates total mitochondrial mass in response to mitochondrial dysfunction. J Cell Sci. 2005; 118: 5357-67. http://dx.doi. org/10.1242/jcs.02645.

10. Wu CC, Taylor RS, Lane DR, Ladinsky MS, Weisz JA, Howell KE. GMx33: a novel family of trans-Golgi proteins identified by proteomics. Traffic. 2000; 1: 963-75. http:// dx.doi.org/10.1111/j.1600-0854.2000.11206.x. 
11. Zhou J, Xu T, Qin R, Yan Y, Chen C, Chen Y, Yu H, Xia C, Lu Y, Ding X, Wang Y, Cai X, Chen J. Overexpression of Golgi phosphoprotein-3 (GOLPH3) in glioblastoma multiforme is associated with worse prognosis. J Neurooncol. 2012; 110: 195-203. http://dx.doi.org/10.1007/ s11060-012-0970-9.

12. Abraham RT. GOLPH3 links the Golgi network to mTOR signaling and human cancer. Pigment Cell Melanoma Res. 2009; 22: 378-9. http://dx.doi. org/10.1111/j.1755-148X.2009.00596.x.

13. Buschman MD, Rahajeng J, Field SJ. GOLPH3 links the Golgi, DNA damage, and cancer. Cancer Res. 2015; 75: 624-7. http://dx.doi.org/10.1158/0008-5472.CAN-14-3081.

14. Halberg N, Sengelaub CA, Navrazhina K, Molina H, Uryu K, Tavazoie SF. PITPNC1 Recruits RAB1B to the Golgi Network to Drive Malignant Secretion. Cancer Cell. 2016; 29: 339-53. http://dx.doi.org/10.1016/j.ccell.2016.02.013.

15. Scott KL, Kabbarah O, Liang MC, Ivanova E, Anagnostou V, Wu J, Dhakal S, Wu M, Chen S, Feinberg T, Huang J, Saci A, Widlund HR, et al. GOLPH3 modulates mTOR signalling and rapamycin sensitivity in cancer. Nature. 2009; 459: 1085-90. http://dx.doi.org/10.1038/nature08109.

16. Dai T, Zhang D, Cai M, Wang C, Wu Z, Ying Z, Wu J, Li M, Xie D, Li J, Song L. Golgi phosphoprotein 3 (GOLPH3) promotes hepatocellular carcinoma cell aggressiveness by activating the NF- $\mathrm{BB}$ pathway. J Pathol. 2015; 235: 490501. http://dx.doi.org/10.1002/path.4479.

17. Qiu CZ, Wang MZ, Yu WS, Guo YT, Wang CX, Yang XF. Correlation of GOLPH3 Gene with Wnt Signaling Pathway in Human Colon Cancer Cells. J Cancer. 2016; 7: 928-34. http://dx.doi.org/10.7150/jca.13968.

18. Wang R, Ke ZF, Wang F, Zhang WH, Wang YF, Li SH, Wang LT. GOLPH3 overexpression is closely correlated with poor prognosis in human non-small cell lung cancer and mediates its metastasis through upregulating MMP-2 and MMP-9. Cell Physiol Biochem. 2015; 35: 969-82. http://dx.doi.org/10.1159/000369753.

19. Zhang Q, Zhuang J, Deng Y, Zhao X, Tang B, Yao D, Zhao W, Chang C, Lu Q, Chen W, Zhang S, Ji C, Cao L, et al. GOLPH3 is a potential therapeutic target and a prognostic indicator of poor survival in bladder cancer treated by cystectomy. Oncotarget. 2015; 6: 32177-92. http://dx.doi. org/10.18632/oncotarget.4867.

20. Feng Y, He F, Wu H, Huang H, Zhang L, Han X, Liu J. GOLPH3L is a Novel Prognostic Biomarker for Epithelial Ovarian Cancer. J Cancer. 2015; 6: 893-900. http://dx.doi. org/10.7150/jca.11865.

21. Hua X, Yu L, Pan W, Huang X, Liao Z, Xian Q, Fang L, Shen H. Increased expression of Golgi phosphoprotein-3 is associated with tumor aggressiveness and poor prognosis of prostate cancer. Diagn Pathol. 2012; 7: 127. http://dx.doi. org/10.1186/1746-1596-7-127.

22. Li Q, Ma Y, Xu W. High GOLPH3 expression is associated with poor prognosis and invasion of hepatocellular carcinoma. Mol Med Rep. 2015; 11: 4315-20. http://dx.doi. org/10.3892/mmr.2015.3267.

23. Tang W, Han M, Ruan B, Jin W, Lou J, Yuan X, Chen D, Chen Y, Shin VY, Jin H, Wang X. Overexpression of GOLPH3 is associated with poor survival in Non-small-cell lung cancer. Am J Transl Res. 2016; 8: 1756-62. https://doi. org/10.1007/s13277-014-2357-3.

24. Xue Y, Wu G, Liao Y, Xiao G, Ma X, Zou X, Zhang G, Xiao $\mathrm{R}$, Wang X, Liu Q, Long D, Yang J, Xu H, et al. GOLPH3 is a novel marker of poor prognosis and a potential therapeutic target in human renal cell carcinoma. Br J Cancer. 2014; 110: 2250-60. http://dx.doi.org/10.1038/bjc.2014.124.

25. Zhu K, Zhao Q, Yue J, Shi P, Yan H, Xu X, Wang R. GOLPH3 overexpression correlates with poor response to neoadjuvant therapy and prognosis in locally advanced rectal cancer. Oncotarget. 2016; 7: 68329-38. http://dx.doi. org/10.18632/oncotarget.12008.

26. Zeng Z, Lin H, Zhao X, Liu G, Wang X, Xu R, Chen K, Li J, Song L. Overexpression of GOLPH3 promotes proliferation and tumorigenicity in breast cancer via suppression of the FOXO1 transcription factor. Clin Cancer Res. 2012; 18: 4059-69. http://dx.doi.org/10.1158/10780432.CCR-11-3156.

27. Nakada M, Nakada S, Demuth T, Tran NL, Hoelzinger DB, Berens ME. Molecular targets of glioma invasion. Cell Mol Life Sci. 2007; 64: 458-78. http://dx.doi.org/10.1007/ s00018-007-6342-5.

28. Ridley AJ, Schwartz MA, Burridge K, Firtel RA, Ginsberg MH, Borisy G, Parsons JT, Horwitz AR. Cell migration: integrating signals from front to back. Science. 2003; 302: 1704-9. http://dx.doi.org/10.1126/science.1092053.

29. Zhou X, Zhan W, Bian W, Hua L, Shi Q, Xie S, Yang D, Li Y, Zhang X, Liu G, Yu R. GOLPH3 regulates the migration and invasion of glioma cells though RhoA. Biochem Biophys Res Commun. 2013; 433: 338-44. http://dx.doi. org/10.1016/j.bbrc.2013.03.003.

30. Ichim G, Tait SW. A fate worse than death: apoptosis as an oncogenic process. Nat Rev Cancer. 2016; 16: 539-48. http://dx.doi.org/10.1038/nrc.2016.58.

31. Al-Batran SE, Hofheinz RD, Pauligk C, Kopp HG, Haag GM, Luley KB, Meiler J, Homann N, Lorenzen S, Schmalenberg H, Probst S, Koenigsmann M, Egger $\mathrm{M}$, et al. Histopathological regression after neoadjuvant docetaxel, oxaliplatin, fluorouracil, and leucovorin versus epirubicin, cisplatin, and fluorouracil or capecitabine in patients with resectable gastric or gastro-oesophageal junction adenocarcinoma (FLOT4-AIO): results from the phase 2 part of a multicentre, open-label, randomised phase 2/3 trial. Lancet Oncol. 2016; 17: 1697-1708. http://dx.doi. org/10.1016/S1470-2045(16)30531-9.

32. Funt SA, Rosenberg JE. Systemic, perioperative management of muscle-invasive bladder cancer and future horizons. Nat Rev Clin Oncol. 2016 ; 14: 221-234. http:// dx.doi.org/10.1038/nrclinonc.2016.188. 
33. Harbeck N, Gnant M. Breast cancer. Lancet. 2016; 18 : 1134 1150. http://dx.doi.org/10.1016/S0140-6736(16)31891-8.

34. Liu J, Blake SJ, Yong MC, Harjunpää H, Ngiow SF, Takeda K, Young A, O'Donnell JS, Allen S, Smyth MJ, Teng MW. Improved Efficacy of Neoadjuvant Compared to Adjuvant Immunotherapy to Eradicate Metastatic Disease. Cancer Discov. 2016; 6: 1382-1399. http://dx.doi. org/10.1158/2159-8290.CD-16-0577.

35. Rugo HS, Olopade OI, DeMichele A, Yau C, van 't Veer LJ, Buxton MB, Hogarth M, Hylton NM, Paoloni M, Perlmutter J, Symmans WF, Yee D, Chien AJ, et al. Adaptive Randomization of Veliparib-Carboplatin Treatment in Breast Cancer. N Engl J Med. 2016; 375: 23-34. http:// dx.doi.org/10.1056/NEJMoa1513749.

36. Yuan H, Chen J, Liu Y, Ouyang T, Li J, Wang T, Fan Z, Fan T, Lin B, Xie Y. Association of PIK3CA Mutation Status before and after Neoadjuvant Chemotherapy with Response to Chemotherapy in Women with Breast Cancer. Clin Cancer Res. 2015; 21: 4365-72. http://dx.doi. org/10.1158/1078-0432.CCR-14-3354.

37. Zhang M, Wei W, Liu J, Yang H, Jiang Y, Tang W, Li Q, Liao X. Comparison of the effectiveness and toxicity of neoadjuvant chemotherapy regimens, capecitabine/ epirubicin/cyclophosphamide vs 5-fluorouracil/epirubicin/ cyclophosphamide, followed by adjuvant, capecitabine/ docetaxel vs docetaxel, in patients with operable breast cancer. Onco Targets Ther. 2016; 9: 3443-50. http://dx.doi. org/10.2147/OTT.S104431.

38. Wang Z, Jiang B, Chen L, Di J, Cui M, Liu M, Ma Y, Yang H, Xing J, Zhang C, Yao Z, Zhang N, Dong B, et al. GOLPH3 predicts survival of colorectal cancer patients treated with 5-fluorouracil-based adjuvant chemotherapy. J Transl Med. 2014; 12: 15. http://dx.doi. org/10.1186/1479-5876-12-15. 